\title{
THE MANAGERIAL DECISION-MAKING MODEL FOR THE MODERNIZATION OF TECHNOLOGIES FOR BUSINESS PROCESSES AT A LARGE INDUSTRIAL ENTERPRISE
}

Anton N. Karamyshev ${ }^{1}$

\begin{abstract}
Existing technologies for processes. In order to provide an substantiating the modernization of basic business processes make it relatively easy to calculate the economic effect of its implementation (by saving resources, reducing labor intensity, increasing both labor productivity and production volumes) because all calculations are based primarily on linear relationships. The rationale for the modernization of auxiliary business processes is more problematic since their specific features significantly complicate the calculation of the economic effect. Firstly, there is a lack of information about the technologies for supporting auxiliary business processes. Secondly, the existing management tools do not consider the complex and closed nature of economic relations between supporting business processes. Thirdly, the complexity of assessing the quality of products of auxiliary business processes opportunity to justify business process modernization projects, the author has developed a model that evaluates the effectiveness of a managerial decision on modernization based on changes in the total profit of the enterprise, which differs from the existing ones taking into account the cyclical nature of economic relationships between auxiliary business processes. The developed model for managerial decision-making for the modernization of business process technologies at a large industrial enterprise is based on the author's method of calculating the cost of production of a large machine-building enterprise, taking into account the principle of multi-cyclical distribution of the cost of auxiliary business processes.

Keywords: enterprise management, industry, modernization, model.
\end{abstract} and their impact on the main business

\footnotetext{
${ }^{1}$ Kazan Federal University. e-mail: antonkar2005@yandex.ru. Tel.: +7-960-067-65-50
} 


\section{$1 \quad$ Introduction}

The most important factors that ensure the competitiveness and stable position of an industrial enterprise in a globalized open economy are profit, production costs, and sales profitability. The performance of the main and auxiliary business processes has a significant impact on these indicators, and the rationale for their modernization is relevant for industrial enterprises.

\section{$2 \quad$ Main Part}

Since the enterprise is a set of interconnected business processes, the modernization of one of the auxiliary or main business processes affects the performance of the network of business processes and the enterprise in general $[1,2]$.

The simplest is the justification of projects to improve the process equipment of the main (production) business processes, which is carried out by calculating the net present value, payback period, and internal rate of return of the project [3-5]. Justification for the modernization of auxiliary business processes faces the following problems: a) lack of information about auxiliary business processes supporting technologies;

b) the existing management tools doesn't consider the complex and closed nature of economic relations between auxiliary business processes;

c) difficult assessment of the quality of products of auxiliary business processes and their impact on the main business processes.

The developed model for managerial decision-making for the modernization of business process technologies at a large industrial enterprise (Fig. 1) is based on the author's method of calculating the cost of production of a large machinebuilding enterprise, taking into account the principle of multi-cyclical distribution of the cost of auxiliary business processes [6-8]. To be applied in the proposed model, this technique requires its further development, in particular, the following points should be added thereto:

\section{"Calculation of profits from} the sale of the $g$-th product". It is calculated according to the following formula: 


$$
G B_{g}^{c}=G B_{g} \times N_{g}(1)
$$

where $G B_{g}^{c}$ is profit from the

$G B_{g}$ is profit from the sale of a sale of $g$-n products; piece of the $g$-th product.

$N_{g}$ is the volume of the $g$-th product sold during the reporting period (month), pcs.;

$$
G B_{g}=N S_{g}-P C_{g}(2)
$$

where

"Calculation of the total

$N S_{g}$ is revenue from the sale of profit of the enterprise". It is calculated a piece of the $g$-th product; according to the following formula:

$P C_{g}$ is the unit cost of the $g$-th

item.

$$
G B^{c}=\sum_{g=1}^{K} G B_{g}^{c}
$$

where $G B^{c}$ is the total profit of the enterprise;

$K$ is the range of products.

The main criterion characterizing the quality of managerial decisions made in the medium and long term is, in our opinion, profit. If after the decision is made, the profit increases, then this decision can be considered reasonable, and vice versa.

The model for managerial decision-making for the modernization of technologies for business processes at a large industrial enterprise is shown in Figure 1. 


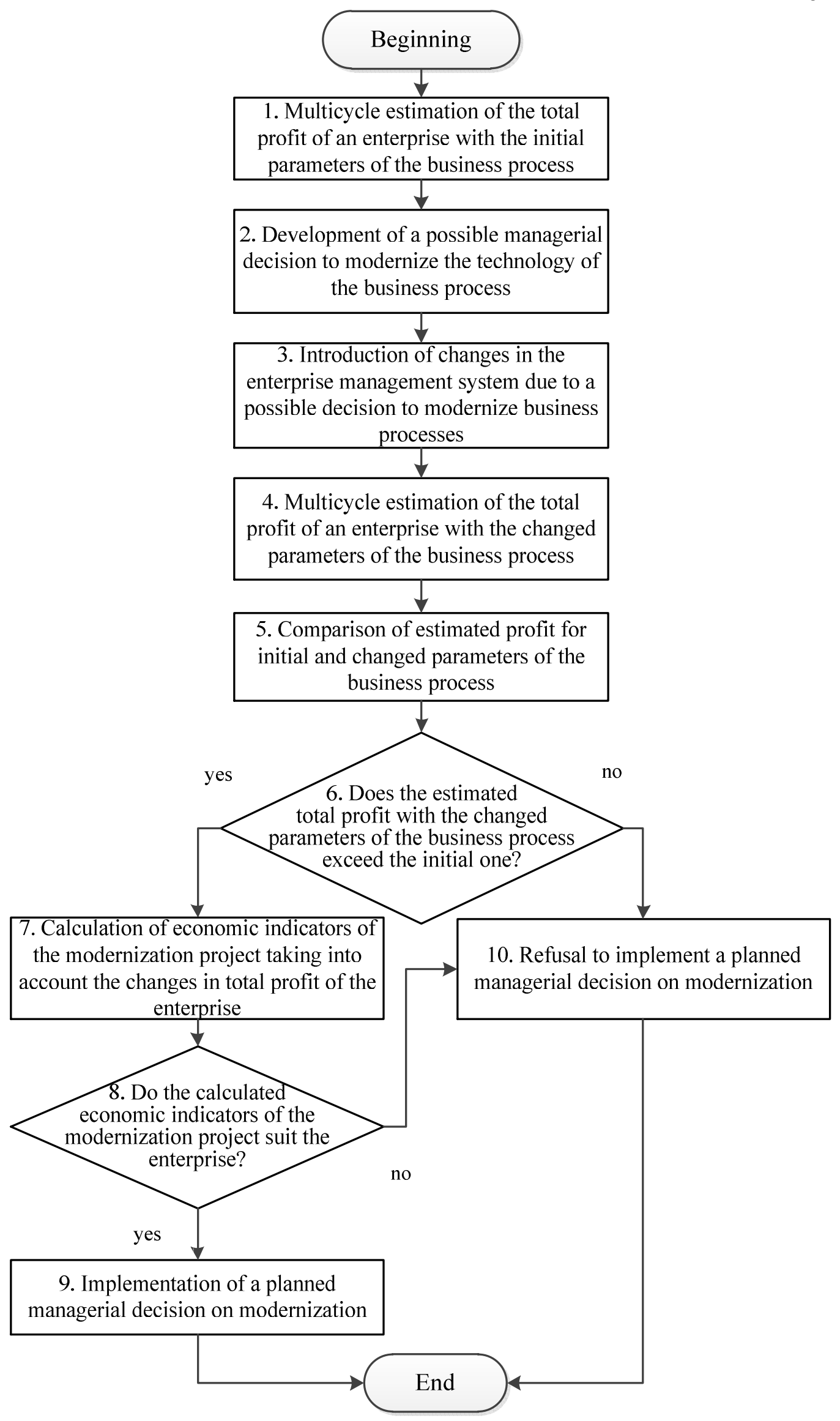


Figure 1. The model for managerial decision-making for the modernization of technologies for business processes at a large industrial enterprise (author's development)

We shall consider the stages of the proposed model.

\section{Stage 1. Multicycle estimation} of the total profit of an enterprise with the initial parameters of the business process.

The implementation of the stage is carried out on the basis of a revised author's methodology for calculating the cost of production of a large machinebuilding enterprise, subject to the principle of multi-cyclical distribution of their cost of auxiliary business processes $[7]$.

The specified methodology for calculating the cost of production of a large industrial enterprise includes the following steps:

Based on the cost estimate of the auxiliary unit, the cost of the products of the auxiliary subprocesses is calculated.

Distribution at the z-th cycle of the cost of the auxiliary subprocess to consumer sub-processes.

Calculation of the cost of products included in the s-th sub-process from sub-processes suppliers at the $\mathrm{z}$-th cycle.

$>\quad$ Check of conditions for cycle termination.

$>$ If the condition for termination of the multicyclic distribution is not fulfilled, the next distribution cycle must be implemented.

$>$ If the condition for termination of the multicyclic distribution is fulfilled, then it is necessary to carry out the final distribution cycle for the cost of auxiliary sub-processes.

Accumulation of the cost of auxiliary sub-processes in the context of the main business processes.

$>$ Calculation of the total cost of the main business processes.

Distribution of the total cost of the main business processes between their operating centers.

Calculation of the cost of the machine-hour of the operating center in terms of general production and general business expenses of the enterprise. 
alculation of the amount of overhead allocated from a unit of operating equipment to the product.

Calculation of the cost of the machine-hour of unutilized capacity of the equipment (in the case, if the regulatory fund of the equipment exceeds the planned value).

alculation of the amount of overhead allocated from a unit of unutilized equipment to the product.

Calculation of the amount of overhead costs for temporarily idle operating centers of the main business process.

Calculation of residual overhead.

Calculation of the cost of production.

The proposed production cost calculation methodology allows:

1. Calculating the budget cost of sub-processes and business processes.

2. Considering the multicyclical nature of the allocation of costs of auxiliary business processes, due to the many relationships of business processes and enterprise sub-processes.
3. Sett(ming the level of accuracy of the distribution of the cost of auxiliary business processes to the main business processes by formulating the conditions for exit from the multi-cycle distribution.

4. Selecting the most appropriate distribution bases based on statistical methods.

5. Calculating the cost of production subject to the multi-cyclical distribution of the cost of auxiliary business processes (overhead costs).

6. Allocating overhead in the unit cost of the product attributable to operating, unutilized, idle equipment.

\section{Stage 2. Development of a} possible managerial decision to modernize the technology of the business process.

At this stage, the equipment to be replaced is determined in the considered main or auxiliary business process; marketing search is carried out in the equipment market; preliminary negotiations are held with the aim of receiving technical and commercial proposals from potential suppliers. In our opinion, at this stage, the development of a business plan for an investment project should be carried out. 
Stage 3. Introduction of changes in the enterprise management system due to a possible decision to

An automated management system requires indicating the relationship of the modified business process with the rest, indicate the cost drivers for further distribution of the cost of this business process, determine the change in input and output products throughout the enterprise's business process network [1,2,10-15].

\section{Stage 4. Multicycle estimation} of the total profit of an enterprise with the changed parameters of the business process.

Based on the changes made in stage 3 , the total profit of the enterprise modernize business processes.

is calculated with a modified business process.

Stage 5. Comparison of estimated profit for initial and changed parameters of the business process.

At this stage, two values are compared: $G B_{\text {before }}^{c}$ (total profit of the enterprise before making a management decision to modernize the business process) $G B_{\text {after (estimated planned }}^{c}$ total profit of the enterprise in case of making a management decision to modernize the business process).

Condition 6. Does the estimated total profit with the changed parameters of the business process exceed the initial one?

Mathematically, this condition can be expressed as follows:

$$
G B_{\text {before }}^{c} \leftarrow G B_{\text {after }}^{c}
$$

If condition (4) is fulfilled, proceed to stage 7; otherwise, proceed to stage 10 .

modernization project taking into account the changes in total profit of the enterprise.

The basic economic indicators Stage 7. Calculation of of the investment project for the economic indicators of the modernization of the business process 
under consideration are calculated: net present value, payback period, and internal rate of return. At the same time, the economic effect of the project is formed by increasing the total profit of the enterprise:

$$
\Delta G B^{c}=G B_{\text {after }}^{c}-G B_{\text {before }}^{c}
$$

where $\Delta G B^{c}$ is the amount the total profit of the enterprise from the implementation of the project has increased by.

\section{Stage 8. Do the calculated} economic indicators of the modernization project suit the enterprise?

If the calculated economic indicators of the modernization project suit the enterprise management, they proceed to stage 9, otherwise, they proceed to stage 10 .

\section{Stage 9. Implementation of a} planned managerial decision on modernization.

At this stage, the implementation of organizational and technical measures provided for by the business plan of the investment project begins.
Stage 10. Refusal to implement a planned managerial decision on modernization.

Management decision that reduces the total profit from sales of products is rejected.

\section{$3 \quad$ Methods}

The study applied the following methods:

1. A selective analysis of specialized literature with a high citation index for the topics indicated in the title of the article. In particular, information was collected on the problems of substantiating the feasibility of modernizing business processes, taking into account the specific features of large machine-building enterprises.

2. The generated array of information was systematized for the purpose of further analysis. In particular, based on the analysis of existing methodologies, a model for managerial decision-making for the modernization of business process execution 
technologies at a large industrial enterprise was proposed, and its advantages and disadvantages were identified.

3. The authors interpreted the results of the study and made conclusions.

\section{$4 \quad$ Results And Discussion}

The proposed model is based on the author's method of calculating the cost of production of a large machinebuilding enterprise, taking into account the principle of multi-cyclical distribution of the cost of auxiliary business processes. To be applied in the proposed model, this technique was extended.

Without a modified cost calculation methodology, the use of the proposed model is problematic since it is based on more accurate calculations of the cost of production of a large machine-building enterprise.

\section{Summary}

The rationale for the modernization of auxiliary business processes is more problematic since their specific features significantly complicate the calculation of the economic effect.
Firstly, there is a lack of information about auxiliary business processes supporting technologies. Secondly, the existing management tools doesn't consider the complex and closed nature of economic relations between auxiliary business processes. Thirdly, difficult assessment of the quality of products of auxiliary business processes and their impact on the main business processes.

\section{Conclusions}

The proposed model of managerial decision-making for the modernization of technology for business processes allows considering the impact of modernization of one or more business processes of the enterprise on their entire network; it differs from the existing ones in taking into account the cyclical nature of economic interconnections between auxiliary business processes.

\section{Acknowledgments}

The work is performed according to the Russian Government Program of Competitive Growth of Kazan Federal University. 


\section{References}

Karamyshev, A.N. 2017 Analysis of the essence of the process approach to enterprise management // Competence. №5. C.47-51.

Karamyshev, A.N. 2018 Analysis of Existing Approaches to Management of Industrial Enterprises // HELIX. Vol.8, Is.1. P.2893-2897.

Karamyshev, A.N. 2017 Bases of acceptance of administrative decisions at the large machine-building enterprises // the Economy and business. № 8. P.3. 996-998 pp.

Karamyshev, A.N. 2017 Analysis of managerial decisions on the modernization of technologies for the implementation of basic and auxiliary business processes of an industrial enterprise // Economics and Entrepreneurship. №2 (Part 2). C.816820 .

Karamyshev A.N. 2017 Analysis of managerial decisions on expanding the range and increasing production volumes // Economics and Entrepreneurship. №7. P.833-836.
226

Karamyshev, A.N. 2017 Multicycle principle of attributing the cost of supporting business processes to commodity production cost in large industrial enterprises // Turkish Online Journal Of Design Art And Communication. Vol.7, Is. - P.16751685.

Karamyshev, A.N. (2016). A technique for calculating the cost of production of a large machine-building enterprise, taking into account the principle of multicyclic distribution of the cost of auxiliary business processes // Economics and Entrepreneurship. № 12 (Part 3). P.1054-1061.

Karamyshev, A.N. 2017 Algorithm for completing the multicyclic attribution of the cost of auxiliary subprocesses to the main business processes of an industrial enterprise // Vestnik BSTU. VG Shukhov. №2. P. 233-235.

Karamyshev, A.N. 2017 A technique for calculating the cost of auxiliary business processes of a large machine-building enterprise taking into account their closed cyclic interrelations // Economics 
and Entrepreneurship. № 5 (Part 1). P.

563-568.

Hammer, M. 1995 The Reengineering

Revolution: A Handbook. New York:

Harper Collins. 130 p.

Harmon, P. 2014 Business Process

Change. NY: Morgan Kaufmann. 520 p.

Burlton, R. 2001 Business Process

Management: Profiting From Process.

NY: Sams. p.232

Mahal, A. 2010 How Work Gets Done:

Business Process Management, Basics

and Beyond. New Jersey: Technics

Publications, LLC. 193 p.

Mahal, A. 2014 Facilitators and Trainers

Toolkit. New Jersey: Technics

Publications, LLC. 295 p.

Rummler, G.A., Brache, A.P. 2012

Improving Performance: How to

Manage the White Space on the

Organization Chart. NY: John Wiley \&

Sons. 288 p. 